\title{
Success Rate of Hysteroscopy and Endometrial Scratching in Repeated Implantation Failure: A Randomized Controlled Clinical Trial
}

\author{
Ziba Zahiri ${ }^{1,2}$, Yasaman Sarrafzadeh ${ }^{1,2}{ }^{\mathbb{}}$, Ehsan Kazem Nejad Leili ${ }^{3}$, Alireza Sheibani ${ }^{4}$
}

\author{
${ }^{1}$ Reproductive Health Research Center, Department of Obstetrics and Gynecology, Alzhra Hospital, School of Medicine, Guilan \\ University of Medical Sciences, Rasht, Iran \\ ${ }^{2}$ Mehr Fertility Research Center, Guilan University of Medical Sciences, Rasht, Iran \\ ${ }^{3}$ Social Determinants of Health Research Center (SDHRC), Guilan University of Medical Sciences, Rasht, Iran \\ ${ }^{4}$ Department of Pathology, School of Medicine, Iran University of Medical Sciences, Tehran, Iran
}

\begin{abstract}
Background: Endometrial receptivity is one of the most important factors in vitro fertilization (IVF) success rate. Many different methods have been suggested to enhance the rate of implantation in IVF $\backslash$ intracytoplasmic sperm injection (ICSI) cycles. Endometrial injury, as an intentional trauma aimed at improving the fertility results, has gained significant popularity among women seeking pregnancy. This study was conducted to determine the success rate of hysteroscopy and scratching before microinjection in cases of repeated implantation failure. Materials and Methods: This prospective, randomized controlled trial consist of 228 women who were referred to the Al-Zahra Infertility clinic for fertility treatment with the history of failure in at least two ICSI cycles. The patients were divided into two groups. The first group was treated by hysteroscopy without intervention, while the second group underwent hysteroscopy and scratching in the luteal phase of the menstrual cycle prior to microinjection cycle. The controlled ovarian stimulation (COS) was performed in all patients using the antagonist method. The success was considered based on the observation of the fetal heart activity in ultrasound. Results: The success rate of hysteroscopy and scratching (41.5\%) was higher compared to hysteroscopy alone (34.3\%), but this difference was not statistically significant based on the Chisquare test $(\mathrm{P}=0.280)$. The rate of miscarriage in hysteroscopy plus scratching and hysteroscopy alone were $5.7 \%$ and $12.4 \%$, respectively which were not statistically different $(\mathrm{P}=888)$. Furthermore, the effect of hysteroscopy and scratching on visualizing the fetal heart activity was not statistically different compared to hysteroscopy alone ( $\mathrm{P}=0.223$ ). Conclusion: The results showed that the success rate in hysteroscopy plus endometrial scratching was not significantly different from hysteroscopy alone. [GMJ.2021;10:e1399] DOI:10.31661/gmj.v10i0.1399
\end{abstract}

Keywords: Infertility; Hysteroscopy; Endometrial Scratching

\section{GMJ}

Copyright $\subset$ 2021, Galen Medical Journal. This is an open-access article distributed under the terms of the Creative Commons Attribution 4.0 International License (http://creativecommons.org/licenses/by/4.0/) Email:info@gmj.ir

\footnotetext{
Correspondence to:

Reproductive Health Research Center, Department of Obstetrics \& Gynecology, Azzhra Hospital, School of Medicine, Guilan 


\section{Introduction}

I nfertility is defined as not being able to become pregnant after a year of unprotected intercourse. Infertility is also considered for a woman who can get pregnant but keeps having miscarriage or stillbirths [1]. With the advancement in science and technology in the field of infertility treatment in recent decades, physicians and researchers have started to exercise the effectiveness of artificial insemination methods, generally referred to as Assisted Reproductive Technologies (ARTs). The outcome of ART has been favorable and considerable [2-4]. The ARTs include the in-vitro (outside the body) direct oocyte manipulation. The intracytoplasmic sperm injection (ICSI) method refers to sperm injection into the cytoplasm, which is performed by an embryologist in the laboratory. In a method called microinjection, sperm is injected into the ovum using advanced techniques, following which the fertilization and cell division would occur. This method involves the injection of sperm to the center of each mature ovum so the fertility can occur. In each in vitro fertilization (IVF) cycle, one or two embryos are transferred to the womb. No additional embryo is transferred in this cycle, and the unused ones will be frozen for later use [5].

In most cases, the rate of ICSI fertilization is similar to that of the normal IVF in the absence of male factors, which ranges from $50 \%$ to $70 \%$. So far, researchers have tried several methods to improve the rate of implantation in IVF/ICSI cycles. However, the endometrium has been the most considering issue in these efforts. Implantation of an embryo within the endometrial cavity is a critical step in ART. Inflammation is a process that is originated from infection due to microbes, viruses, or mechanical trauma, including tissue injury. Mechanical endometrial injury (biopsy, scratching or hysteroscopy) in the cycle preceding ovarian stimulation for IVF has been proposed to improve implantation in women with unexplained recurrent implantation (RIF) [6]. Endometrial scratching has attracted much attention and has quickly become incorporated into clinical practice to advance implantation [7]. It has been discovered that mechanical operation of the endometrium can get improve receptivity by changing gene expression of parameters needed for implantation, including laminin alpha 4 , integrin alpha 6 , and matrix metalloproteinase1 [8]. Studies on animal models have confirmed that scratching the endometrium irritate the decidualization and as a result, improve the receptivity of endometrium [9]. Conflicting results exist in human studies. Barash et al. [10] confirmed that multiple endometrial biopsies at special times of the IVF cycle were related to elevated pregnancy rate. Furthermore, Zhou et al. [11] established that injuries induced in local endometrium in controlled ovarian stimulation (COS) cycles were related to elevated pregnancy rate. Conversely, Karimzade et al. [12] demonstrated that injuries induced in local endometrium on the day of ova pickup disturbs the receptive endometrium and has a negative effect on implantation rate in IVF cycles. Due to the controversial results about the effect of endometriosis scratch on successful pregnancy and the lack of a study on the simultaneous effect of hysteroscopy and scratch of the endometrium, this study tries to measure the effect of these two factors on the success rate of pregnancy in fertilization methods.

\section{Materials and Methods}

\section{Patients}

In this prospective randomized controlled trial study, 228 women seeking fertility referred to the Al-Zahra Infertility Clinic were enrolled. All eligible patients, based on the inclusion criteria, were divided into two groups after obtaining informed consent and before conducting the microinjection cycle (Figure-1).

\section{Sample Size Calculation}

The sample size was calculated using the following formula.

P: 0.05; Z : Z-score; $90 \%-$ Z Score $=1.645$.

We chose $90 \%$ confidence level.

\section{Inclusion and Exclusion Criteria}

Inclusion criteria were a history of ICSI failure at least twice, age under 40 years, $\mathrm{FSH} \leq 12$, having normal ultrasound assessment of uterus (including myometrium and endometrium), normal hysterosalpingography (HSG) or normal laparoscopy assessment. 


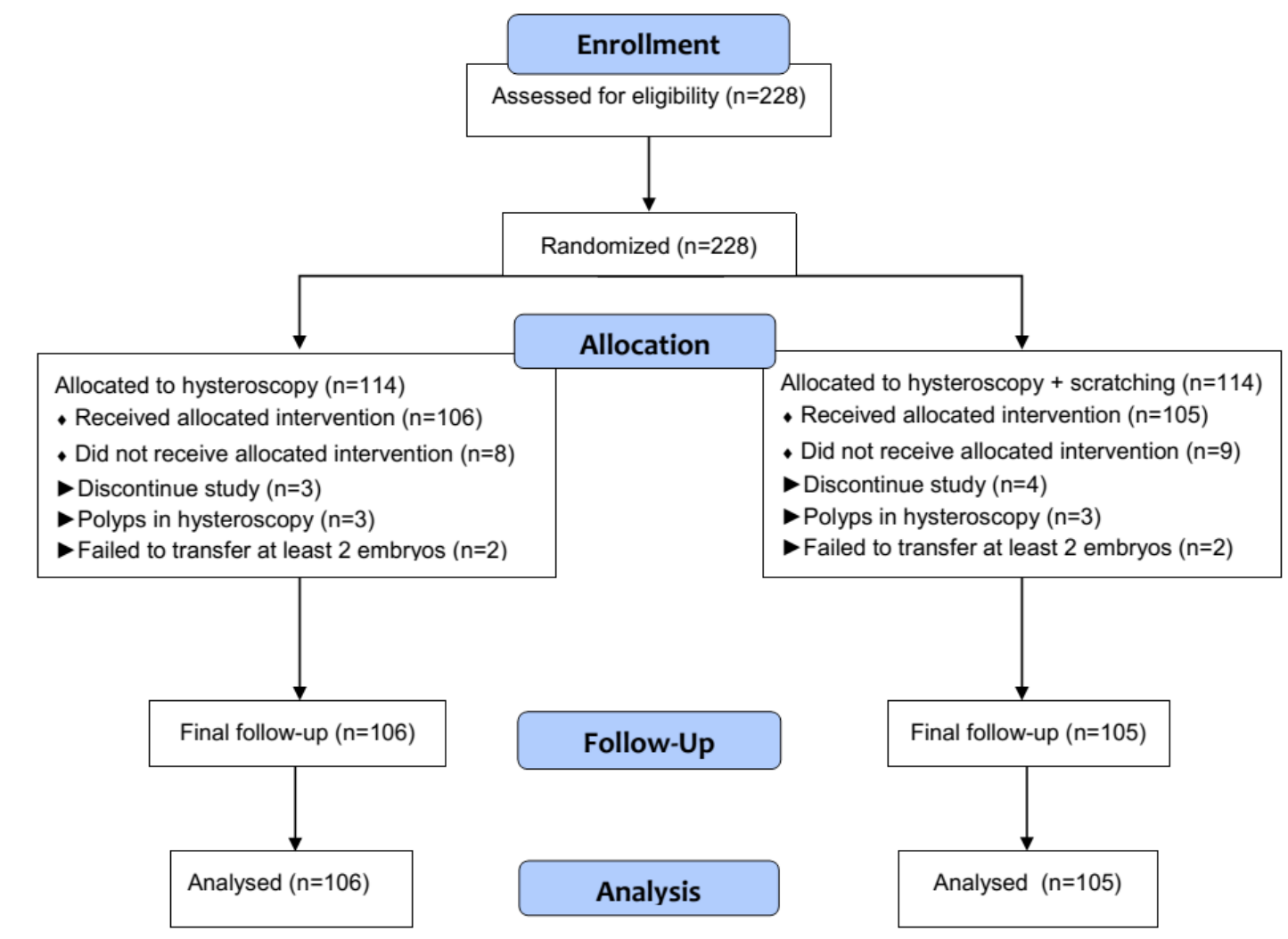

Figure 1. Consort flowchart of study

The exclusion criteria were any endometrial lesion in hysteroscopy including myoma, polyp, Asherman's syndrome or Mullerian anomaly, un availability of at least two embryos of good quality, ovarian hyperstimulation syndrome (OHSS), serum progesterone above $1.5-2$, having diabetes mellitus, CRF, thyroid disorders, kidney or hepatic diseases, smoking or being exposed to cigarette smoke for at least three months prior to the interventions

\section{Intervention}

The first group was treated by hysteroscopy without intervention, while the second group underwent hysteroscopy and scratching in the luteal phase of the menstrual cycle prior to the microinjection procedure. In the case of diagnosing any endometrial lesions, including polyps-fibroma-adhesion or Müllerian anomaly during hysteroscopy, the patient was excluded from the study. In the second group, the patients underwent hysteroscopy along with endometrial scratching by a curette on four sides of the endometrium (anterior, posterior, and two lateral sides). The COS was performed for all patients using an antagonist protocol. Thus, two tablets of 2-mg estradiol daily were prescribed for all patients from the $21^{\text {st }}$ day of the last menstrual cycle. The estradiol consumption was discontinued after the menstruation started before the administration of gonadotropins. Then, treatment with gonadotropins, including a combination of recombinant follicular stimulating hormone (FSH, Gonal F, Merck Serono, Switzerland) along with a human menopausal gonadotrophins (HMG, Monogon, Ferring, Germany) based on the patient's age and the evaluation of previous ovarian response in last cycles, antral follicle count (AFC), and anti-Mullerian hormone (AMH) was begun. The antagonist (Cetrotide 0.25, Merck Serono, Germany) was administrated subcutaneously once daily from the 5th day of gonadotropins treatment. Serial ultrasonography with hormonal monitoring was performed to evaluate the growth status of follicles as needed. In case of the presence of at least 3 follicles $\geq 18 \mathrm{~mm}, 10000$ unit of HCG IM or $0.2 \mathrm{mg}$ of Decapeptyl SC, (Ferring, Germany) was administered. About 36 hours later, the oocytes were extracted un- 
der ultrasound guide and general anesthesia, and 2 to 3 days later, the embryo was transferred into the uterus using a Labotect catheter. Progesterone was administered at a dose of $100 \mathrm{mg}$ per day from the day of ovum pick up and was continued for 14 to 16 days when pregnancy test was performed. If the pregnancy test was positive, the medications were continued, and an ultrasound examination was conducted around 6-7 weeks of gestation to assess the status of pregnancy and the observation of the fetal heart activity. In the case of pregnancy, the rate of multiple pregnancies and the rate of abortion were monitored and followed up to the 12th week (early abortion).

\section{Outcomes}

Success was determined based on three variables including fetal heart activity, multiple pregnancies, and abortion. The fetal heart activity and multiple pregnancies were assessed using ultrasound, and abortion was confirmed based on the loss of gestational products before the 12th-week gestation.

\section{Ethical Statements}

The protocol of this study was approved by the Ethical Committee of Guilan University of Medical Sciences (approval code: IR.GUMS. REC.1396.54) and was registered in the Iranian Registry of Clinical Trials (RCT ID: IRCT201708081306N9). Written informed consent was obtained from all participants.

Statistical Analysis

The statistical package for social sciences (SPSS) software version 21 (SPSS Inc, Chi- cago, IL) was used for data analysis. Descriptive analysis was performed using mean, standard deviation, frequency and percentage, and plotting tables. Quantitative variables were expressed as mean $\pm \mathrm{SD}$, and qualitative variables were expressed as numbers and percentages. To compare the frequency of fetal heart activity, abortion, multiple pregnancy between groups, the chi-square and Fisher exact tests were used. The student t-test was used to compare the fetal heart activity between groups. If the distribution of data for a variable was not parametrical, the Mann-Whitney test was used for comparison. In order to determine the effect of scratching on the success of pregnancy, logistic regression was used controlling for age and body mass index (BMI). The odds ratio (OR) of the matched non-dimensional (scratching effect on the endometrium) was estimated based on this model. A 95\% confidence interval for OR was used to express the estimation accuracy. The P-value smaller than 0.05 was considered statistically significant. Study outcomes were fetal heart activity, abortion and multiple pregnancy.

\section{Results}

In this study, no significant difference was observed between groups in terms of age $(\mathrm{P}=0.074)$ and BMI $(\mathrm{P}=0.693$, Table-1). Seventy-five percent of the study population lived in the city ( $25 \%$ lived in the rural area). Sixtyfive percent of the study population had the education level of diploma or below diploma, while $35 \%$ had academic education. There was a significant difference between groups in

Table 1. Comparison of Age and BMI in the Two Studied Groups

\begin{tabular}{|c|c|c|c|c|c|}
\hline & & \multirow{2}{*}{$\begin{array}{c}\text { Hysteroscopy } \\
\text { alone } \\
\text { n(\%) }\end{array}$} & \multirow{2}{*}{$\begin{array}{c}\text { Hysteroscopy }+ \\
\text { Scratching } \\
\text { n(\%) }\end{array}$} & \multicolumn{2}{|c|}{ Total } \\
\hline & & & & n(\%) & P-value \\
\hline \multirow{3}{*}{ Age } & $\leq 30$ years & $33(31.4 \%)$ & $23(21.7 \%)$ & $56(26.5 \%)$ & 0.074 \\
\hline & $31-40$ years & $72(68.6 \%)$ & $83(78.3 \%)$ & $155(73.5 \%)$ & 0.067 \\
\hline & Total & $105(100.0 \%)$ & $106(100.0 \%)$ & $211(100.0 \%)$ & 0.05 \\
\hline \multirow{4}{*}{ BMI } & $\leq 25$ & $56(53.3 \%)$ & $51(48.1 \%)$ & $107(50.7 \%)$ & 0.693 \\
\hline & $25-30$ & $33(31.4 \%)$ & $35(33.0 \%)$ & $68(32.2 \%)$ & 0.564 \\
\hline & $>30$ & $16(15.2 \%)$ & $20(18.9 \%)$ & $36(17.1 \%)$ & 0.743 \\
\hline & Total & $105(100.0 \%)$ & $106(100.0 \%)$ & $211(100.0 \%)$ & 0.670 \\
\hline
\end{tabular}

BMI: Body mass index 
terms of the duration of infertility $(\mathrm{P}=0.001)$, cause of infertility $(\mathrm{P}=0.004)$, number of previous unsuccessful transfers $(\mathrm{P}=0.004)$, and number of transferred embryos $(\mathrm{P}<0.001)$. The prevalence of causes for infertility, including decreased ovarian reserve, male factor, tubular factors, and unknown cause, were $6.7 \%, 14.3 \%, 47.6 \%$, and $5.7 \%$, respectively in the hysteroscopy group, while these values in the hysteroscopy plus scratching group were $24.5 \%, 17 \%$, and $7.5 \%$, respectively. The male factor was lower in second group compared to the first group. The average number of years of infertili-ty and the number of previous unsuccessful transfers in the second group were higher than the first group, indicating that the subjects in the second group had worse conditions for pregnancy. Furthermore, the number of transferred embryos in the first group was lower than second group, which reduces the likelihood of a successful pregnancy (Table-2). The success rate (fetal heart activity) was $41.5 \%$ in second group and $34.3 \%$ in the first group. This difference was not statistically significant based on the Chi-square test $(\mathrm{P}=0.280)$. The prevalence of abortion was $5.7 \%$ in second group, while it was $12.4 \%$ in the hysteroscopy alone group, which were not statistically different $(\mathrm{P}=$ 0.888 ). The number of multiple pregnancies in the hysteroscopy plus scratching group was $11.3 \%$, while it was $6.8 \%$ in the first group. This difference was not statistically significant $(\mathrm{P}=0.505$, Table-3).

The success rates due to the influence of age group, BMI, duration of infertility, type of infertility, the cause of infertility, and the menstrual cycle characteristic showed no significant difference between study groups $(\mathrm{P}<$ $0.05)$. Furthermore, the percentage of fetal heart observation in the hysteroscopy plus scratching and hysteroscopy alone groups was

Table 2. Comparison of the Variables Studied in the Two Groups

\begin{tabular}{|c|c|c|c|c|c|c|}
\hline & & & Hysteroscopy & $\begin{array}{l}\text { Hysteroscopy } \\
\text { + Scratching }\end{array}$ & Total & P-value \\
\hline \multirow{4}{*}{$\begin{array}{l}\text { Type of } \\
\text { infertility }\end{array}$} & Primary & $\mathrm{n}(\%)$ & $93(88.6 \%)$ & $89(84 \%)$ & $182(86.3 \%)$ & \multirow{3}{*}{0.331} \\
\hline & Secondary & $\mathrm{n}(\%)$ & $12(11.4 \%)$ & $17(16 \%)$ & $29(13.7 \%)$ & \\
\hline & Total & $\mathrm{n}(\%)$ & $105(100 \%)$ & $106(100 \%)$ & $211(100 \%)$ & \\
\hline & PCOS & $\mathrm{n}(\%)$ & $27(25.7 \%)$ & $18(17 \%)$ & $45(21.3 \%)$ & \multirow{6}{*}{0.004} \\
\hline \multirow{5}{*}{$\begin{array}{l}\text { Cause of } \\
\text { infertility }\end{array}$} & $\begin{array}{l}\text { Decreased } \\
\text { ovarian } \\
\text { reserve }\end{array}$ & $\mathrm{n}(\%)$ & $7(6.7 \%)$ & $26(24.5 \%)$ & $33(15.6 \%)$ & \\
\hline & Tubal & $\mathrm{n}(\%)$ & $15(14.3 \%)$ & $18(17 \%)$ & $33(15.6 \%)$ & \\
\hline & Male & $\mathrm{n}(\%)$ & $50(47.6 \%)$ & $36(34 \%)$ & $86(40.8 \%)$ & \\
\hline & Unknown & $\mathrm{n}(\%)$ & $6(5.7 \%)$ & $8(7.5 \%)$ & $14(6.6 \%)$ & \\
\hline & Total & $\mathrm{n}(\%)$ & $105(100 \%)$ & $106(100 \%)$ & $211(100 \%)$ & \\
\hline \multirow{3}{*}{$\begin{array}{l}\text { Menstrual } \\
\text { cycle }\end{array}$} & Regular & $\mathrm{n}(\%)$ & $55(52.4 \%)$ & $51(48.1 \%)$ & $106(50.2 \%)$ & \multirow{3}{*}{0.535} \\
\hline & Irregular & $\mathrm{n}(\%)$ & $50(47.6 \%)$ & $55(51.9 \%)$ & $105(49.8 \%)$ & \\
\hline & Total & $\mathrm{n}(\%)$ & $105(100 \%)$ & $106(100 \%)$ & $211(100 \%)$ & \\
\hline $\begin{array}{l}\text { Duration of } \\
\text { infertility } \\
\text { (years) }\end{array}$ & \multicolumn{2}{|l|}{$\mathrm{M} \pm \mathrm{SD}$} & $7.29 \pm 4.8$ & $9.95 \pm 5.87$ & $8.63 \pm 5.52$ & 0.001 \\
\hline $\begin{array}{c}\text { Number of } \\
\text { previous } \\
\text { failed } \\
\text { transfer } \\
\text { cycles }\end{array}$ & \multicolumn{2}{|l|}{$\mathrm{M} \pm \mathrm{SD}$} & $2.26 \pm .5$ & $2.57 \pm 0.97$ & $2.41 \pm 0.78$ & 0.004 \\
\hline $\begin{array}{l}\text { Number of } \\
\text { transferred } \\
\text { embryos }\end{array}$ & \multicolumn{2}{|l|}{$\mathrm{M} \pm \mathrm{SD}$} & $3.68 \pm 1.11$ & $2.65 \pm 0.78$ & $3.16 \pm 1.09$ & 0.001 \\
\hline
\end{tabular}


Table 3. The Percentage Rate of Studied Endometrial Local Scratching Methods

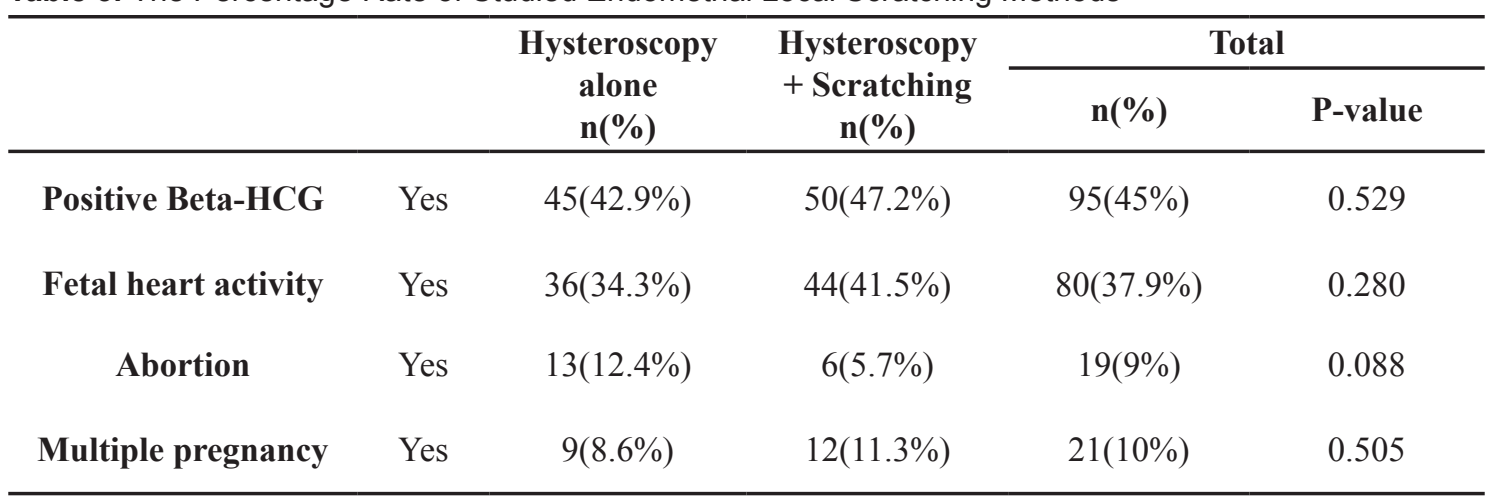

statistically significant in subjects with a previous failure microinjection rate $\geq 3$. In other words, in cases with a higher number of previous unsuccessful transfer, the success rate of scratching (based on fetal heart observation) was improved (Table-4). The multiple logistic regression model, using Backward LR method, was performed controlling for the effects of intervening variables (age, BMI, the cause of infertility, menstrual cycle characteristic, duration of infertility years as well as the number of previously failed transfers and the number of transferred embryos). Table-5 shows that the relationship between scratching and the fetal heart observation in the matched model was still not significant $(\mathrm{P}=0.232)$. The chance of observing fetal heart increased by increasing BMI and the number of transferred embryos. In samples whose infertility was due to lack of ovulation, the chance of observing fetal heart increased. Furthermore, the chance of observing fetal heart was higher in samples with male factor infertility, compared to polycystic ovarian syndrome (PCOS).

\section{Discussion}

This study was performed to determine the success rate of hysteroscopy plus scratching versus hysteroscopy alone before microinjection in cases of RIF. The study results suggested that the hysteroscopy plus scratching approach did not lead to success in fetal heart observation, multiple pregnancies, and abortion in comparison to hysteroscopy alone. The poor endometrial receptivity could initiate unexplained infertility since it was established that in unexplained infertility, there was a lower expression of some genes and proteins linked to uterine implantation. Therefore, a decreased endometrial receptivity has been proposed as a reason in couples with unexplained infertility. Likewise, in women with PCOS, poor endometrial receptivity has been proposed as a factor involved in infertility because the endometrium becomes less receptive due to suboptimal endometrial regulation [13]. Many investigators examined the consequence of endometrial injury on pregnancy rate in couples who tried to conceive without IVF/ICSI cycles either by normal sexual intercourse or intrauterine insemination (IUI). Inducing stromal cell decidualization or inducing wound healing response may activate the release of some inflammatory factors, including cytokines and growth factors that improve embryo implantation, which can be the underlying cause for the effect of endometrial injury on pregnancy rate [14]. A randomized controlled trial was conducted by Gibreel et al. on 105 patients with unexplained infertility. The study aimed to test the effect of endometrial injury by pipelle in the luteal phase in comparison to advice for regular marital life with unprotected intercourse for the next 6 months. The results showed that Clinical pregnancy rate was significantly higher in the women experiencing endometrial scratch in comparison to the control group $(25.9 \%$ and $9.8 \%$, respectively). However, this study had two main limitations including small sample size and no prior power calculation [15]. In our study, no significant difference was observed between two groups. The difference in observation in our study and the previous study can be due to the difference in sample size and in the characteristics of the study groups. El-Toukhy et al. studied performed a 
study on outpatient subjects who underwent hysteroscopy before IVF and had the normal uterine ultrasound and a history of unsuccessful IVF [16]. They found that scratching did not improve the living birth rate. Similarly, the results of studies by Yee et al. [17], Tehrani Nejad et al. [18], and Farzadi et al. [19] indicated did not improve the live birth rate with endometrial local scratching method. In accordance with these studies, our results showed that scratching had no benefits on ICSI outcomes. Ko et al. mentioned a positive impact of scratching on the IVF outcome in women with RIF. However, according to them, this measure would not be effective in infertile or low fertile women who have been randomly undergone IVFs [20]. Parsanezhad et al. found that the pregnancy rate was considerably higher in the endometrial injury group compared to the control group (17/114,
$14.9 \%$ versus $6 / 103,5.8 \%$ ) in patients who intrauterine insemination [21]. They concluded that endometrium local mechanical injury can improve the uterine receptivity and help the embryo implantation. The results of studies by Zhou et al. showed that local injury (scratching) in the endometrium area during a $\mathrm{COH}$ cycle improves the rate of implantation, clinical pregnancy and the live birth of the ART cycles [11]. In this study, a specific day was considered for endometrial scratching, and this date is mainly chosen to be in the luteal phase. In another study, the incidence rate of pregnancy was reported to be $14.9 \%$ in the endometrial biopsy group compared to the control group 5.8\% in control group which was statistically significant difference [22]. In their study, the subjects' age ranged from 25 to 35 years, while the subjects in our study were 40 years old or younger. The age may be ef-

Table 4. Comparison of Success Rate (Fetal Heart activity) Between Two Groups

\begin{tabular}{|c|c|c|c|c|}
\hline \multicolumn{2}{|c|}{ Variable } & \multirow{2}{*}{$\begin{array}{c}\text { Hysteroscopy } \\
12(36.4 \%)\end{array}$} & \multirow{2}{*}{$\begin{array}{c}\text { Hysteroscopy + Scratching } \\
9(39.1 \%)\end{array}$} & \multirow{2}{*}{$\begin{array}{c}\text { P-value } \\
0.833\end{array}$} \\
\hline $\mathbf{A} \sigma \alpha$ & 30 years or lower & & & \\
\hline Age & 31 to 40 years & $24(33.3 \%)$ & $35(42.2 \%)$ & 0.259 \\
\hline \multirow{3}{*}{ BMI } & $\leq 25$ & $15(26.8 \%)$ & $18(35.3 \%)$ & 0.341 \\
\hline & $25-30$ & $11(33.3 \%)$ & $19(54.3 \%)$ & 0.082 \\
\hline & $>30$ & $10(62.5 \%)$ & $7(35 \%)$ & 0.101 \\
\hline \multirow{2}{*}{$\begin{array}{l}\text { Infertility } \\
\text { duration }\end{array}$} & 5 years or less & $20(37.7 \%)$ & $13(38.2 \%)$ & 0.963 \\
\hline & Over 5 years & $16(30.8 \%)$ & $31(43.1 \%)$ & 0.164 \\
\hline \multirow{2}{*}{$\begin{array}{l}\text { Number of } \\
\text { previous failed } \\
\text { transfer cycles }\end{array}$} & 2 and less & $32(39.5 \%)$ & $29(40.8 \%)$ & 0.867 \\
\hline & 3 and more & $41(6.7 \%)$ & $15(42.9 \%)$ & 0.034 \\
\hline \multirow{2}{*}{$\begin{array}{c}\text { Number of } \\
\text { Transferred } \\
\text { embryos }\end{array}$} & $2-3$ & $8(29.6 \%)$ & $25(50 \%)$ & 0.085 \\
\hline & 4 and more & $28(35.9 \%)$ & $19(33.9 \%)$ & 0.814 \\
\hline \multirow{3}{*}{ Infertility type } & Primary & $31(33.3 \%)$ & $37(41.6 \%)$ & 0.251 \\
\hline & Secondary & $5(41.7 \%)$ & $7(41.2 \%)$ & 0.972 \\
\hline & PCO & $4(14.8 \%)$ & $6(33.3 \%)$ & 0.143 \\
\hline \multirow{4}{*}{$\begin{array}{l}\text { Causes of } \\
\text { infertility }\end{array}$} & $\begin{array}{c}\text { decreased } \\
\text { ovarian reserve }\end{array}$ & $6(85.7 \%)$ & $12(46.2 \%)$ & 0.062 \\
\hline & Tubal & $4(26.7 \%)$ & $7(38.9 \%)$ & 0.458 \\
\hline & Male & $20(40 \%)$ & $16(44.4 \%)$ & 0.680 \\
\hline & Unknown & $2(33.3 \%)$ & $3(37.5 \%)$ & 0.872 \\
\hline \multirow{3}{*}{ Menstrual cycle } & Regular & $20(36.4 \%)$ & $21(41.2 \%)$ & 0.611 \\
\hline & Irregular & $16(32 \%)$ & $23(41.8 \%)$ & 0.298 \\
\hline & Total & $36(34.3 \%)$ & $44(41.5 \%)$ & 0.280 \\
\hline
\end{tabular}

BMI: Body mass index; PCOS: Polycystic ovary syndrome 
Table 5. Logistic Regression Model by the Backward LR Method

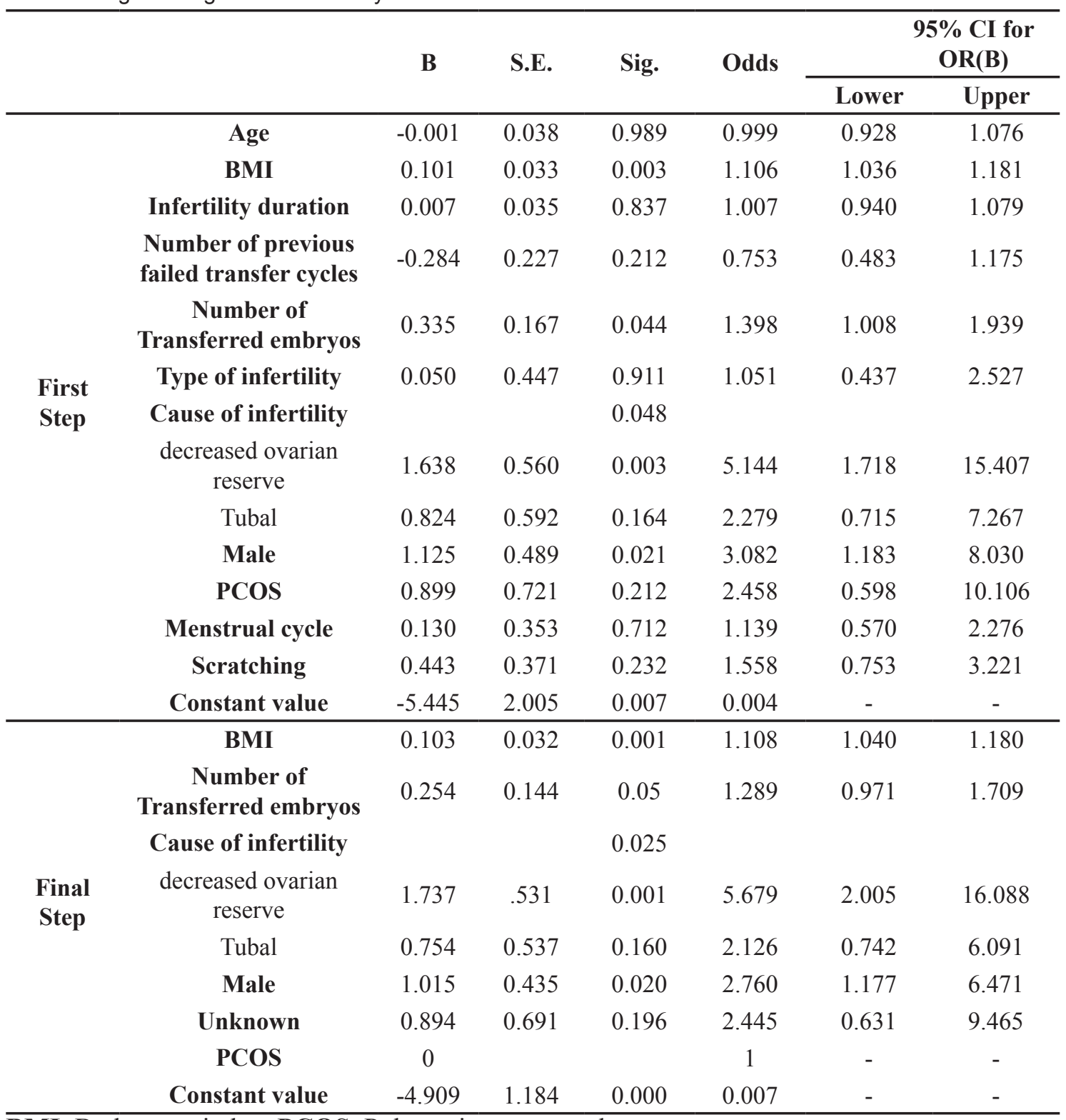

BMI: Body mass index; PCOS: Polycystic ovary syndrom

fective in the failure of scratching in the fetal heart observation. Narvekar et al. conducted a study on 100 eligible patients with a history of IVF failure despite good quality embryos [23]. Endometrial sampling was performed in the follicular and luteal phase by Pipelle in the non-transferring cycle in the intervention group. The results indicated an increase in the implantation and live birth rate in the intervention group. In this study, the endometrial scratching was performed in both luteal and follicular phases, while we only performed the scratching procedure in the luteal phase in our study. The results of the study by Potdar et al. revealed that local endometrial scratching performed before the ovarian cycle increases the likelihood of pregnancy by about $70 \%$ compared to the control group. Furthermore, the evidence was in favor of the hypothesis that inducing local endometrial damage before the ovarian cycle can improve the pregnancy outcomes in women with RIF with the unknown cause [6]. In this study, the sample size was large, which can be effective in the frequency of variables. In the study by Weal et al., the patients with a history of one IVF failure despite good quality embryo who underwent endometrial scratching using suction 
on day 5-7 of the same transfer cycle. The results indicated an improvement in the implantation at the same cycle [24]. In this study, the endometrial scratching was performed in the same cycle, while we did the procedure in the previous cycle. A recently published randomized controlled trial that enrolled 144 women concluded that endometrial injury in the cycle previous to IUI did not affect the clinical pregnancy rate [25]. It is suggested to perform extensive studied in this area to obtain more accurate results in the context and to determine the more effective factors. This can lead to taking effective steps in increasing the success rate in the cases of RIF. The results of this study could also be a basis for future studies in this area. However, our study had some limitation. One of the limitations of our study was that the intervention was carried out only in one phase (luteal). The other limitation was the scratch type. It is advisable that the intervention group be divided into different groups and the effect of different types of scratch on the outcome measures be compared between groups. This will help identify the most effective type of injury to achieve favorable outcomes in embryo transfer.

\section{Conclusion}

Subjects with the history of 3 or more embryo transfer failures controlling for the cause of infertility (due to male factor, tubular factor, ovulatory and unexplained infertility), duration of infertility, and number of previous unsuccessful transfer benefited from endome- trial scratching. Thus, this could explain the claim that, given the worse conditions of the hysteroscopy plus scratching group, the individuals with three or more previous failed transfers were exposed infertility due to various endometrial factors. Perhaps, an endometrial scratching can be effective by creating an inflammatory environment and eliminating the endometrial unfavorable conditions for implantation and subsequent observation of fetal heart activity. Various influencing variables, including predetermined cycle for performing pre-IVF scratching (previous cycle or few previous cycles), the performed phase (luteal or proliferative), number of endometrial scratching, endometrial scratching performance in the luteal phase, the extent of damage in the scratching procedure and awareness of choosing the right method for local endometrial damage may also be effective in the ultimate success rate.

\section{Acknowledgment}

This study was financially supported by the Vice-Chancellorship of Research and Technology, Guilan University of Medical Science. Ethical approval was obtained from the ethics committee of the Vice-Chancellor of Research at Guilan University of Medical Sciences (code: IR.GUMS.REC.1396.54).

\section{Conflict of Interest}

There was no conflict of interest.

\section{References}

1. Ramezani M, Ashtiyani S, Shamsi M, Taheri $\mathrm{S}$. The opinion and views of Rhaze, $\mathrm{s}$, Avicenna, s and Jorjani, s views on fertility and infertility. Asia Pac J Oncol Nurs. 2013;3(2):504-15.

2. Rohani Z, Naroienejad M. Evaluation of the prevalence of fallopian tube abnormality in primary and secondary infertility based on hysterosalpingography findings. Razi Journal of Medical Sciences. 2007;13(53):105-11.

3. Behdani R. Laparoscopic study on 75 cases of secondary infertility in Roointan Arash Hospital, 1993-96. Arch Iran Med.
2000;58(1):87-91.

4. Nyboe Andersen A, Goossens V, Bhattacharya S, Ferraretti A, Kupka M, De Mouzon J, et al. Assisted reproductive technology and intrauterine inseminations in Europe, 2005: results generated from European registers by ESHRE: ESHRE. The European IVF Monitoring Programme (EIM), for the European Society of Human Reproduction and Embryology (ESHRE). Hum Reprod. 2009;24(6):1267-87.

5. Agostini F, Monti F, Fagandini P, De Pascalis LLD, La Sala GB, Blickstein I. Parental 
mental representations during late pregnancy and early parenthood following assisted reproductive technology. J Prenat Med. 2009;37(4):320-7.

6. Potdar N, Gelbaya T, Nardo LG. Endometrial injury to overcome recurrent embryo implantation failure: a systematic review and meta-analysis. Reproductive biomedicine online. 2012;25(6):561-71.

7. Almog B, Shalom-Paz E, Dufort D, Tulandi T. Promoting implantation by local injury to the endometrium. Int J Fertil Steril. 2010;94(6):2026-9.

8. Mirkin S, Arslan M, Churikov D, Corica A, Diaz J, Williams S, et al. In search of candidate genes critically expressed in the human endometrium during the window of implantation. Hum Reprod. 2005;20(8):210417.

9. Finn C, Martin L. Endocrine control of the timing of endometrial sensitivity to a decidual stimulus. Biol Reprod. 1972;7(1):82-6.

10. Barash A, Dekel N, Fieldust S, Segal I, Schechtman E, Granot I. Local injury to the endometrium doubles the incidence of successful pregnancies in patients undergoing in vitro fertilization. Int J Fertil Steril. 2003;79(6):1317-22.

11. Zhou L, Li R, Wang R, Huang H-x, Zhong K. Local injury to the endometrium in controlled ovarian hyperstimulation cycles improves implantation rates. Int J Fertil Steril. 2008;89(5):1166-76.

12. Karimzade MA, Oskouian H, Ahmadi S, Oskouian L. Local injury to the endometrium on the day of oocyte retrieval has a negative impact on implantation in assisted reproductive cycles: a randomized controlled trial. Obstet Gynecol Int. 2010;281(3):499503.

13. Wu M, Yin Y, Zhao M, Hu L, Chen Q. The low expression of leukemia inhibitory factor in endometrium: possible relevant to unexplained infertility with multiple implantation failures. Cytokine. 2013;62(2):334-9.

14. Gnainsky Y, Granot I, Aldo PB, Barash A, Or Y, Schechtman E, et al. Local injury of the endometrium induces an inflammatory response that promotes successful implantation. .Int J Fertil Steril. 2010;94(6):2030-6.

15. Gibreel A, Badawy A, El-Refai W, El-Adawi N. Endometrial scratching to improve pregnancy rate in couples with unexplained subfertility: a randomized controlled trial. J Obstet Gynaecol Res. 2013;39(3):680-4.

16. El-Toukhy T, Campo R, Khalaf Y, Tabanelli C, Gianaroli L, Gordts SS, et al. Hysteroscopy in recurrent invitro fertilisation failure (TROPHY): a multicentre, randomised controlled trial. The Lancet. 2016;387(10038):2614-21.

17. Yeung TWY, Chai J, Li RHW, Lee VCY, Ho PC, Ng EHY. The effect of endometrial injury on ongoing pregnancy rate in unselected subfertile women undergoing in vitro fertilization: a randomized controlled trial. Hum Reprod . 2014;29(11):2474-81.

18. Shahrokh Tehraninejad E, Dashti M, Hossein Rashidi B, Khorrami N, Azimi Nekou E. Evaluating the effects of local endometrial injury on the success rate of frozen embryo transfer (FET). Research in Medicine. 2015;39(3):121-6.

19. Farzadi L, Fakour A, Ghasemzadeh A, Hamdi K, Fard SA, Nouri M, et al. The effect of local endometrial injury and GnRH agonist on pregnancy rate in patients with recurrent implantation failure. Int J Womens Health Reprod Sci. 2016;4:34-7.

20. Ko Jky, Ng Ehy. Scratching and IVF: any role?. Curr Opin Obstet Gynecol. 2016;28(3):178-83.

21. Parsanezhad ME, Dadras N, Maharlouei N, Neghahban L, Keramati P, Amini M. Pregnancy rate after endometrial injury in couples with unexplained infertility: A randomized clinical trial. Iran J Reprod Med. 2013;11(11): 869-74.

22. Fleming TP, Watkins AJ, Velazquez MA, Mathers JC, Prentice AM, Stephenson J, et al. Origins of lifetime health around the time of conception: causes and consequences. The Lancet. 2018; ;391(10132):1842-1852.

23. Narvekar SA, Gupta N, Shetty N, Kottur A, Srinivas M, Rao KA. Does local endometrial injury in the nontransfer cycle improve the IVF-ET outcoe in the subsequent cycle in patients with previous unsuccessful IVF? A randomized controlled pilot study. J Hum Reprod Sci. 2010;3(1): :15-9.

24. Nossair WS, El Behery MM, Farag MAS. Endometrial scratch-suction and implantation failure. Open J Obstet Gynecol. 2014;4(05): 217-227.

25. Zarei A, Alborzi S, Dadras N, Azadi G. The effects of endometrial injury on intrauterine insemination outcome: A randomized clinical trial. Iran J Reprod Med. 2014;12(9): 649-52. 